\title{
The Influence of Lead (II) Ions Introduced into the Subphase on the Stability of Mixed "Polyamic Acid + Surfactant" Monolayers and Manufacturing of Dye-containing Langmuir-Blodgett Polymeric Films
}

\author{
Olga N. Bezkrovnaya, ${ }^{a}$ Nikolay O. Mchedlov-Petrossyan, ${ }^{*, b}$ Yuriy N. Savvin, ${ }^{a}$ Aleksandr V. Tolmachev ${ }^{a}$ \\ and Natalya A. Vodolazkaya \\ ${ }^{a}$ Institute for Single Crystals, National Academy of Sciences of Ukraine, Lenin Pr. 60, Kharkov, 61001 Ukraine \\ ${ }^{b}$ Department of Physical Chemistry, V.N. Karazin Kharkov National University, Svoboda Sq. 4, \\ Kharkov, 61077, Ukraine
}

\begin{abstract}
Descrevemos as condições de preparação, em solução aquosa, de monocamadas de ácido poliamínico (PA) contendo um grupo $\mathrm{COOH}$ por unidade de repetição. A presença de íons $\mathrm{Pb}^{2+}$ na subfase aquosa favorece a manutenção do polímero na superfície aquosa, enquanto as monocamadas são instáveis em subfase de água pura. O comportamento dos filmes de PA em interaces água/ar foi examinado em pH 5,8-6,0 numa concentração de $1 \times 10^{-5} \mathrm{~mol} \mathrm{~L}^{-1}$ de nitrato de chumbo. Foi estudada a influência do álcool $n$-octadecil e do brometo de $n$-octadecilpiridina no carácter das isotermas e na estabilidade das monocamadas. A área limitante por unidade de repetição, $S_{\mathrm{m}}$, aumenta com o aumento da fração de sufactante nas misturas (PA+álcool $n$-octadecil) e (PA+brometo de $n$-octadecilpiridina). Os valores de $S_{\mathrm{m}}$, pressão de colapso e de compressibilidade dos filmes, foram tabulados. Usando as monocamadas poliaminicas, filmes Langmuir-Blodgett monocamada-(60-80) contendo diversos pigmentos (Rhodamina, rosa de Bengala-B e vermelho de quinaldina) foram preparados por depósito em suporte de vidro (quartzo), pelo método de Scheafer. Os espectros de absorção e emissão desses filmes foram registrados. O conteúdo de pigmento variou entre 6 e $\approx 30$ de fração molar. Os espectros de absorção Vis dos filmes poliméricos de monocamada (60-80), contendo rosa de Bengala-B e vermelho de quinaldina, medidos após agitação com fase aquosa tamponada, se mostraram dependentes do $\mathrm{pH}$ desta. $\mathrm{O}$ valor de $\mathrm{p} K_{\mathrm{a}}^{\mathrm{a}}$ aparente encontrado para o vermelho de quinalina em filmes (PA+ álcool $n$-octadecil), obtido por método padrão espectrofotométrico, foi de $2,3 \pm 0,3$. Esse tipo de resposta ao $\mathrm{pH}$ para polímeros multicamadas pode ser usado em sensores.
\end{abstract}

The conditions for the preparation of monolayers of polyamic acid (PA) with one $\mathrm{COOH}$ group per repeating unit on aqueous subphases are described. It is revealed that the presence of $\mathrm{Pb}^{2+}$ ions in the aqueous subphase favors keeping up the polymer on the water surface, while the monolayers are unstable on the pure aqueous subphase. The behavior of PA films on water/air interfaces is examined mainly at pH 5.8-6.0 and $1 \times 10^{-5} \mathrm{~mol} \mathrm{~L} \mathrm{~L}^{-1}$ lead nitrate. The influence of $n$-octadecyl alcohol and $n$ octadecylpyridinium bromide on the character of isotherms and stability of monolayers is studied. The limiting area per repeating unit, $S_{\mathrm{m}}$, increases along with the increase of surfactant fraction in the initial (PA $+n$-octadecyl alcohol) and (PA $+n$-octadecylpyridinium bromide) mixtures. The $S$ values, collapse pressures, and compressibilities of the films are tabulated. Basing on these polyamic monolayers, Langmuir - Blodgett (60-80)-monolayer films containing various dyes (Rhodamine dye, rose Bengal B, and quinaldine red) are fabricated by depositing on glass (quartz) support by Schaefer method. Absorption and emission spectra of these films are registered. The dye content was as a rule 6 to $\approx 30$ mole $\%$. Vis absorption spectra of polymeric (60-80) monolayer films containing rose Bengal $\mathrm{B}$ and quinaldine red, measured after soaking in aqueous buffer solution, appeared to be sensitive to the $\mathrm{pH}$ values of the latter. The 'apparent' $\mathrm{p} K_{\mathrm{a}}^{\mathrm{a}}$ value of quinaldine red in (PA + octadecyl alcohol) films, as determined by standard spectroscopic procedure, equals $2.3 \pm 0.3$. Such $\mathrm{pH}$ response of polymeric multilayers can be used in sensors.

Keywords: water/air interface, polyamic acid, dye-containing Langmuir-Blodgett films, absorption, $\mathrm{pH}$ response

* e-mail: mchedlov@univer.kharkov.ua 


\section{Introduction}

This paper aims to find optimal conditions for obtaining monolayers of polyamic acid (PA) with one $\mathrm{COOH}$ group on aqueous lead-containing subphase and to prepare dye-containing Langmuir - Blodgett films based on such kind of PA monolayers.

Ordered films prepared by the Langmuir - Blodgett technology find application in designing the elemental base of electronic devices, light emitting diodes, as models of bio-membranes, in optical chemical sensors, for instance, containing immobilized acid-base indicators etc. ${ }^{1-7}$ The Langmuir - Blodgett method allows to obtain ordered uniform multilayers, which is of especial interest for creation of structures containing both organic and inorganic components, for further using in nanotechnology. Among other substances, high-molecular-weight compounds are extensively used for such purposes due to their high thermal, mechanical, and chemical stability.

It is of common knowledge that low-molecular-weight substances, forming monomolecular films, must be not only non-volatile, but also amphiphilic and water-insoluble. However, this is unnecessary in the case of macromolecular monolayers. The majority of the substances used in Langmuir - Blodgett technology are amphiphilic, but polymeric molecules without expressed amphiphility, such as polymethylmetacrylate, or even water-soluble derivatives of cellulose and polyvinyl alcohol are also reported to form monolayers on water surfaces. ${ }^{1}$

Polyamic acids are often used for the preparation of Langmuir - Blodgett multilayers. ${ }^{1,5,6,8}$ It is accepted though, that these polymers themselves are too hydrophilic to form stable monolayers on the surface of water. ${ }^{9}$ The introduction of long alkyl chains into the repeating units $^{2,4,10}$ or salt formation with long-tailed amines s,5-7,10 $^{3,5}$ are known to increase the stability of the PA monolayers.

Polyamic acids, $\mathbf{1}$ and $\mathbf{2}$, have the general formula given below,

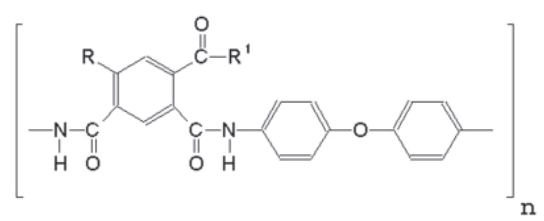

$\mathbf{1}$ is (4,4'-diphenyloxide)-2-carboxyisophthalamide, with $\mathrm{R}=\mathrm{H}, \mathrm{R}^{1}=\mathrm{OH}$, and 2 is (4,4'-diphenyloxyde)-4,6dicarboxyisophthalamide, with $\mathrm{R}=\mathrm{COOH}, \mathrm{R}^{1}=\mathrm{OH}$. Though both polymers contain hydrophobic portions, they are not hydrophobic enough to form stable Langmuir films on aqueous surface. ${ }^{910}$ The presence of alkyl chains makes the macromolecules more hydrophobic and favors the formation of stable and condensed films. ${ }^{2-4,10}$ In the case of 2, for $\mathrm{R}=\mathrm{CO}-\mathrm{O}\left(\mathrm{CH}_{2}\right)_{17}-\mathrm{CH}_{3}$ and $\mathrm{R}^{1}=\mathrm{O}-\left(\mathrm{CH}_{2}\right)_{17}-\mathrm{CH}_{3}$ the limiting area per repeating unit, $S_{\mathrm{m}}$, equals $60 \AA^{2}, 2$ while for $\mathrm{R}=\mathrm{CO}-\mathrm{O}-\left(\mathrm{CH}_{2}\right)_{15}-\mathrm{CH}=\mathrm{CH}_{2}$ and $\mathrm{R}^{1}=\mathrm{O}-\left(\mathrm{CH}_{2}\right)_{15}-$ $\mathrm{CH}=\mathrm{CH}_{2}$ the $S_{\mathrm{m}}$ value is equal to $64 \AA^{2}{ }^{2}{ }^{4}$ In the case of $\mathbf{1}$, at $\mathrm{R}=\mathrm{H}$ and $\mathrm{R}^{1}=\mathrm{O}-\left(\mathrm{CH}_{2}\right)_{17}-\mathrm{CH}_{3}, S_{\mathrm{m}}=63 \AA^{2} .{ }^{9}$ The salt formation of PA with amines also results in the appearance of more stable films with somewhat larger $S_{\mathrm{m}}$ values. For 2, adding 4-(17-octadecenyl)pyridine, $\mathrm{NC}_{5} \mathrm{H}_{4}-\left(\mathrm{CH}_{2}\right)_{16}$ $\mathrm{CH}=\mathrm{CH}_{2}$, leads to $S_{\mathrm{m}}=92 \AA^{2} .^{3}$ A still larger $S_{\mathrm{m}}$ value, $S_{\mathrm{m}}=$ $140 \AA^{2}$, was observed for $2-N, N$-dimethyloctadecylamine salt: $\mathrm{R}=\mathrm{CO}-\mathrm{O}^{-}{ }^{+} \mathrm{H}\left(\mathrm{CH}_{3}\right)_{2} \mathrm{~N}-\mathrm{C}_{18} \mathrm{H}_{37}, \mathrm{R}^{1}=\mathrm{O}^{-}{ }^{+} \mathrm{H}\left(\mathrm{CH}_{3}\right)_{2} \mathrm{~N}-$ $\mathrm{C}_{18} \mathrm{H}_{37}{ }^{5-7}$ At $1: N, N$-dimethyloctadecylamine ratios $1: 1$, $1: 2$, and $2: 1$, the $S_{\mathrm{m}}$ values equal correspondingly $c a$. $80 \AA^{2}, c a .90 \AA^{2}$, and $c a .60 \AA^{2} .{ }^{10}$

So far, the hydrophobic properties of PA have been increased by introducing long alkyl tails into the structure. ${ }^{2-4,9,10}$ Therefore, the method of stabilization of monolayers by the introduction of metal ions, able to form interfacial salts with PA, is of certain interest. Namely, lead (II) ions can be used, which is of special value in view of the possibility of further production of semiconductor Langmuir - Blodgett films after sulfide treatment $\left(\mathrm{Pb}^{2+} \rightarrow \mathrm{PbS}\right){ }^{8}$ The manufacturing of dyecontaining polymeric multilayers stabilized with $\mathrm{Pb}^{2+}$ is also to be examined.

The structure of monolayers of high-molecular-weight compounds containing $\mathrm{COOH}$ groups can be controlled by varying $\mathrm{pH}$ in the subphase or/and introducing metal ions. ${ }^{1,11-13}$ So, the addition of $\mathrm{Cd}^{2+}$ and $\mathrm{La}^{3+}$ ions into an aqueous subphase improves the stability of the co-polymer of methacrylic acid and methylmethacrylate, ${ }^{14}$ while the presence of $\mathrm{Ca}^{2+}$ ions favors the disappearance of the region of the liquid-expanded state from the $(\pi-A)$ isotherm and the formation of a condensed layer of proteins. ${ }^{11}$ Recently we have demonstrated, that the presence of $\mathrm{Pb}^{2+}, \mathrm{Mn}^{2+}$, and $\mathrm{Ag}^{+}$ions in the subphase contributes to holding polymer chains of $\mathbf{2}$ on the water/air interface. ${ }^{15}$ The binding of metal ions by the polymer monolayers was proved by analyzing the corresponding Langmuir - Blodgett films, obtained on silicon substrates by the Schaefer method, using X-ray photoelectron spectroscopy. ${ }^{15}$

It must be pointed out that introduction of doubly charged metal ions is often used in order to increase the stability of Langmuir and Langmuir - Blodgett films formed by fatty acids, e.g. stearic, arachidic etc. ${ }^{16-18}$ The phenomenon was re-examined and studied in details within the past decade. . $^{171}$

The structure of a Langmuir - Blodgett film, transferred onto the substrate, depends on the quality of the monolayer on the interface and conditions of multilayer structures 
formation. While preparing finely-grained highly ordered monolayers on the substrate, in order to avoid their hollowness and decrease in the coefficient of transfer, the monolayer stability problem acquires primary importance. The methods of determination of time stability (decrease of area with time $)^{22}$ and hysteresis studies ${ }^{23,24}$ complement each other. Meanwhile, the behavior of PA monolayers under changing conditions of their preparation on the water subphase has been poorly studied up to now. ${ }^{1-10}$ Previously we reported the conditions for preparation of $\mathbf{2}$ monolayers on lead-containing subphases at various $\mathrm{pH}$ values. ${ }^{15}$

However, monolayers of PA with one $\mathrm{COOH}$ group per repeating unit, $\mathbf{1}$, are certainly more hydrophobic as compared with those with two $\mathrm{COOH}$ groups and therefore more perspective for further using in preparation of multilayers. Meanwhile, corresponding detailed studies for polyamic acid of $\mathbf{1}$ type are practically absent.

The purpose of the present work was to study the stability of $\mathbf{1}$ monolayers under different conditions for their formation on aqueous subphase. The problem of monolayer stability is of importance for the preparation of high-quality Langmuir - Blodgett films. We also report the first results of manufacturing dye-containing Langmuir - Blodgett films based on such kind of PA monolayers.

\section{Experimental}

\section{Materials}

In this work, we studied compression isotherms of Langmuir monolayers of oligomeric $\mathbf{1}$ with the molecular weight of repeating units equal to $374 \mathrm{~g} \mathrm{~mol}^{-1}$. The sample was synthesized at Chernigov Pedagogical University by the standard procedure ${ }^{25}$ and identified at the Department of the Chemistry of High-Molecular-Weight Compounds, Kiev National University; some experiments were also made with 2 sample (molecular weight of repeating units equal to $418 \mathrm{~g} \mathrm{~mol}^{-1}$ ), described earlier. ${ }^{15}$ The polymer solutions were prepared with concentration $5 \times 10^{-4} \mathrm{~mol} \mathrm{~L}^{-1}$; the solvent was a $1: 1$ mixture of $N, N$-dimethylacetamide (reagent grade, additionally distilled) and trichloromethane (reagent grade).,2,9,10 Such a solvent appeared to be most appropriate for obtaining all kinds of monolayers, including the dye-containing ones. $\mathrm{Pb}\left(\mathrm{NO}_{3}\right)_{2}, \mathrm{H}_{2} \mathrm{SO}_{4}, \mathrm{KOH}$, $n$-octadecyl alcohol (ODA), and n-octadecylpyridinium bromide (ODPB) were of reagent grade, doubly distilled water was used for preparation of the subphase. Reagent grade chemicals were used for preparation of buffer systems (borate, phosphate, $o$-phthalate, and tetraoxalate) and $\mathrm{HCl}$ solutions, applied for creating the $\mathrm{pH}$ values in experiments with dye-containing multilayers.
The sample of dye rose Bengal B was purified by column chromatography, quinaldine red iodide of USSR origin (Minkhimprom) was used as such, and $n$-heptadecyl rhodamine B perchlorate of high purity was prepared by Dr. V. I. Alekseeva, Research Institute of Organic Intermediates and Dyes, Moscow, Russia.

\section{Apparatus}

Measurements were performed in a two-sectional Langmuir trough $\left(6.5 \times 60 \mathrm{~cm}^{2}\right)$ constructed in Research Institute of Organic Intermediates and Dyes, Moscow, Russia. The two-dimensional pressure (surface pressure), $\pi$, was measured with a Wilhelmy balance $\left( \pm 0.3 \mathrm{mN} \mathrm{m}^{-1}\right)$ at $20.0 \pm 0.5{ }^{\circ} \mathrm{C}$. The $S_{\mathrm{m}}$ values were obtained by extrapolation of the linear section of the isotherm up to the $A$ axis; the accuracy of $S_{\mathrm{m}}$ determinations was $\pm(1-2)$ $\AA^{2}$. Measurements of $\mathrm{pH}[ \pm(0.04-0.1)]$ were performed using a pH-340 pH meter (Factory of measurement instruments, Gomel, Belarus) with a glass indicator electrode and a standard silver-chloride reference electrode. Vis absorption spectra of dye-containing Langmuir - Blodgett films were obtained by using the Specord M 40 apparatus, emission spectra - with Hitachi F-4010. The lead content in the films was determined by X-ray Photoelectron Spectroscopy (an XPS800 instrument manufactured by Kratos).

\section{Procedure}

The monolayers of $\mathbf{1}$ were spread from the mixed $N, N$ dimethylacetamide - trichloromethane solvent onto twicedistilled water ( $\mathrm{pH} 5.8-6.0)$ at $20{ }^{\circ} \mathrm{C}$; as a rule, $0.12-0.16$ $\mathrm{mL}$ of organic solution were used in each experiment. In the experiments with ODA and ODPB, the appropriate amounts of these surfactants $\left(c a \cdot 10^{-3} \mathrm{~mol} \mathrm{~L}{ }^{-1}\right)$ were dissolved in the initial mixed organic solvent together with 1. The initial surface concentrations of 1 were $5.0 \times 10^{-5}$ to $5.0 \times 10^{-4} \mathrm{mg} \mathrm{cm}^{-2}$. The state of monolayers on the water surface was studied by constructing following curves: $(i)$ compression isotherms, $\pi$ vs. $A$ ( $A$ - area per repeating unit); (ii) hysteresis curves; (iii) stability curves, $A_{t} / A_{0}$ vs. $t$, $\left(A_{t}\right.$ : area per repeating unit in the present instant of time $t$, min; $A_{0}$ : initial area of the repeating unit). All the area values, $A$, $A_{t}, A_{0}$, including the experiments with ODA and ODPB addition, are expressed in $\AA^{2}$. In 5 min after depositing PA, the 'waiting' time necessary for monolayer spreading over the surface of the aqueous subphase, the organic solvent evaporation and molecules accommodation, compression at a rate of $c a$. $10 \AA^{2} \mathrm{~min}^{-1}$ per repeating unit of polymer ${ }^{5,6,10}$ was performed using the non-wettable barrier. The content 
of lead in the subphase optimal for the preparation of monolayers was found to be $1 \times 10^{-5} \mathrm{~mol} \mathrm{~L}^{-1}$, in agreement with earlier studies. ${ }^{15}$

While obtaining the stability curves, the drop of surface pressure to a constant value after stopping the barrier was taken into account. Therefore the monolayer was allowed to stand during $5 \mathrm{~min}$ and then compressed to a constant value $20 \mathrm{mN} \mathrm{m}^{-1}$, which was maintained constant within the whole period of measurements.

While studying of the hysteresis, the monolayer was compressed to $\pi=20 \mathrm{mN} \mathrm{m}^{-1}$. After $10 \mathrm{~min}$ the barrier was moved to the initial area value, $A_{0}$. Then we performed the second compression-expansion cycle. Surface pressure relaxation of 1 films $\left(\Delta \pi_{1}\right.$ and $\Delta \pi_{2}$ ) was measured by compressing a film to the same surface pressure, stopping compression and maintaining the film at constant area during $10 \mathrm{~min}$.

We obtained altogether $\mathrm{ca}$. 100 compression isotherms; the most typical ones are considered below. All the areas were referred to repeating unit of $\mathbf{1}$.

To obtain the monolayers, containing the dyes, the last-named were dissolved in trichloromethane (initial dye concentrations $\mathrm{ca} \cdot 10^{-3} \mathrm{~mol} \mathrm{~L}^{-1}$ ) and thus introduced into the solution of $\mathbf{1}$ and ODA (or ODPB) in the above mentioned mixture of $\mathrm{N}, \mathrm{N}$-dimethylacetamide and $\mathrm{CHCl}_{3}$. Rose Bengal B was introduced in molecular form while the cationic dyes in form of corresponding salts. All the further procedures were as described above.

To manufacture the dye-containing Langmuir Blodgett films of 1 with ODA or ODPB, the dyecontaining monolayers obtained on lead-containing subphase were deposited on glass and quartz support by Schaefer method; the most appropriate values were 30 , 25 , and $20 \mathrm{mN} \mathrm{m}^{-1}$ in the case of rhodamine dye, rose Bengal B, and quinaldine red, respectively. These values, corresponding to liquid-condensed state of monolayers, were found following the procedure described in literature. ${ }^{1,6}$ In all these cases, the mixtures $(\mathbf{1}+$ dye $)$ or $(\mathbf{1}$ + surfactant + dye) were spread in form of mixed solutions in $\left(N, N\right.$-dimethylacetamide $\left.+\mathrm{CHCl}_{3}\right)$ solvent. Before using, the surfaces of the supports were thoroughly purified with peroxide-ammonia mixture ${ }^{5}$ and washed with double distilled water, acetone, and trichloromethane. The total number of monolayers in the Langmuir - Blodgett films was as a rule $60-80$, in order to ensure high enough optical absorbance. However, some experiments were performed also with films containing 30 monolayers. Glass plates with the deposited dye-containing multilayers were placed for 5-10 min in aqueous buffer solutions with known $\mathrm{pH}$ values, and the spectra were recorded after drying several minutes on air. The corresponding PA films without dyes, containing the same amounts of ODA or ODPB, were prepared in the same manner and used as blanks in the spectroscopic measurements.

\section{Results and Discussion}

\section{Search for optimal experimental conditions}

The monolayers of $\mathbf{1}$, like those of previously studied $2,{ }^{15}$ appeared to be unstable on the pure aqueous subphase. This agrees with the results available from literature and can be explained by strong hydrophilic properties of polyamic acids, ${ }^{2}$ which causes the well-known effect of 'dangling' of macromolecules into water (partial diving of chains into the water environment). ${ }^{26}$ Maybe, partial dissolution of the monolayer in the subphase can also take place because of polymer polydispersity and hence existence of fractions with relatively low molecular weights.

Earlier we found that in the system $(2+$ ODA $+n$ octadecylamin), the polymer is satisfactorily held on water/air interface. However, the main studies were performed with lead-containing subphases, in order to obtain more stable monolayers with less complicated composition, keeping in mind further fabrication of semiconductor multilayers too. ${ }^{8}$ All the $(\pi-A)$ isotherms presented below are obtained on lead-containing subphase.

Addition of lead (II) to the aqueous subphase favors the formation of liquid-condensed films of polyamic acids, evidently due to binding of $\mathrm{Pb}^{2+}$ ions by $-\mathrm{COO}^{-}$groups. Interfacial salts thus formed are probably hydrophobic enough to hold the polymer chains on water/air interface. The content of lead in the subphase was as a rule $1 \times 10^{-5} \mathrm{~mol} \mathrm{~L}^{-1}$.

Preliminary experiments with $\mathbf{1}$, in accord with our studies with $2,{ }^{15}$ demonstrated that introduction of either acid or alkali impairs the stability of monolayers. Small amounts of $\mathrm{H}_{2} \mathrm{SO}_{4}$ and $\mathrm{KOH}$ allowed to obtain the subphases with pH 4.6 and 11.0, respectively. The $S_{\mathrm{m}}$ values for $\mathbf{1}$ and 2 in the case of slightly acidic subphase are $c a$. 45-47 $\AA^{2}$ and $53 \AA^{2}$, respectively. With slightly alkaline subphase, the decrease in the $S_{\mathrm{m}}$ values was registered, along with formation of liquid-expanded films. At $\mathrm{pH} 11.0$, the compressibility of $\mathbf{1}$ is much higher, while at $\mathrm{pH} 4.6$ it is somewhat smaller than that of $\mathbf{2}$. At the same time, at both $\mathrm{pH}$ values the reproducibility of the compression isotherms decreases as compared with that in case of pure water.

Thus, we decided to study more precisely the formation, compression-decompression and stability of $\mathbf{1}$ monolayers on aqueous subphases with $1 \times 10^{-5} \mathrm{~mol} \mathrm{~L}^{-1}$ $\mathrm{Pb}\left(\mathrm{NO}_{3}\right)_{2}$. The $\mathrm{pH}$ value of the subphase 5.8-6.0 corresponds to aqueous solution with neither acid nor alkali additives. 
The $\mathrm{p} K_{\mathrm{a}}$ of benzoic acid in water is $4.20 .{ }^{27}$ The presence of peptide groups positioned ortho and para with respect to the carboxyl group should noticeably decrease the $\mathrm{p} K_{\mathrm{a}}$ values; as a result, the majority of carboxyl groups can be considered ionized $\left(\mathrm{COOH} \rightarrow \mathrm{COO}^{-}\right)$at $\mathrm{pH} \geq 5.8$. The interaction of carboxyl groups, including the $\mathrm{COO}^{-}$groups, with $\mathrm{Pb}^{2+}$ ions in aqueous solutions is characterized by stability constants of $c a \cdot 10^{2}-10^{3} .{ }^{28}$ On the other hand, $\mathrm{Pb}^{2+}$ ions remain unchanged in solutions only in fairly acid media. Their stepwise hydrolysis is characterized by the total formation constants of hydroxo-complexes,

$\mathrm{Pb}^{2+}+i \mathrm{OH}^{-} \rightleftarrows \mathrm{Pb}(\mathrm{OH})_{i}^{2-i}, \beta_{i}$

At ionic strength $I=3 \mathrm{~mol} \mathrm{~L}^{-1}, \log \beta_{1}=6.3, \log \beta_{2}=$ 10.8, and $\log \beta_{3}=10.8$. At $I \rightarrow 0, \log \beta_{1}=6.9$ and $\log \beta_{2}=11.5 .^{28}$ The low initial concentrations of lead ions allow us to ignore the presence of polynuclear hydroxocomplexes in solution as a first approximation. Estimates show that no more than $1 \%$ of the $\mathrm{Pb}^{2+}$ ions are converted to $\mathrm{PbOH}^{+}$at $\mathrm{pH}$ 5.8-6.0.

The compression isotherms appeared to be reproducible, which confirms the stability of $\mathbf{1}$ monolayers on water/air interface in the presence of $\mathrm{Pb}^{2+}$ ions, in line with the data for some other polymers. ${ }^{1}$ The lead content in monolayers was checked by analysing corresponding Langmuir - Blodgett films using X-ray photoelectron spectroscopy. The $C_{\mathrm{Pb}} / C_{\mathrm{N}}$ ratio was on average 0.23 . This indicates binding of one lead cation per two repeating units of polymer, i.e., one $\mathrm{Pb}^{2+}$ ion per two $\mathrm{COO}^{-}$groups. After 5 min soaking in aqueous buffer solutions with $\mathrm{pH}=1.68$ and 9.18 , the $C_{\mathrm{Pb}} / C_{\mathrm{N}}$ ratio decreases to 0.036 and 0.127 , correspondingly. The probable reason is protonation of $\mathrm{COO}^{-}$groups in acidic region, leading, as usual, ${ }^{17-21}$ to decay of their complex with metal ions, and hydroxo complexes formation at high $\mathrm{pHs}$ (see above).

The measurements of compression isotherm of $\mathbf{1}$ on aqueous subphase with $1 \times 10^{-5} \mathrm{~mol} \mathrm{~L}^{-1} \mathrm{~Pb}\left(\mathrm{NO}_{3}\right)_{2}$ lead to a value $S_{\mathrm{m}}=(52 \pm 2) \AA^{2}$ (Table 1). The polymer monolayer on lead-containing subphase can be regarded as being in liquid-expanded state. Some typical examples of $(\pi-A)$ isotherms as well as other figures are given in the Supplementary Information.

Preliminary experiments demonstrated that introduction of ODA or ODPB into the initial $\mathbf{1}$ solution results in the increase in the collapse pressure $\pi_{c}$. Therefore it seemed to be important to examine in detail how the additions of these nonionic and cationic surfactants influence the properties of the aforementioned $\mathbf{1}$ monolayers on the lead-containing subphases.
Table 1. Characteristics of $\pi-A$ isotherms of mixed layers on $\mathrm{Pb}^{2+}-$ containing subphases

\begin{tabular}{lccccc}
\hline Mixtures & $\begin{array}{c}\mathrm{S}_{\mathrm{m}} / \AA^{2} \\
\pm(1-2)\end{array}$ & $\begin{array}{c}\pi_{\mathrm{c}} / \\
\left(\mathrm{mN} \mathrm{m}^{-1}\right)\end{array}$ & \multicolumn{2}{c}{$\delta /\left(\mathrm{m}(\mathrm{mN})^{-1}\right)$ at different $\pi$} \\
\hline $\mathbf{1}$ & 52 & 18 & 0.035 & - & - \\
$\mathbf{1}+$ ODA, $r=1$ & 62 & 42 & 0.035 & 0.016 & 0.013 \\
$\mathbf{1}+$ ODA, $r=0.5$ & 47 & 43 & 0.039 & 0.023 & 0.018 \\
$\mathbf{1}+$ ODA, $r=0.33$ & 41 & 43 & 0.026 & 0.025 & 0.010 \\
$\mathbf{1}+$ ODA, $r=0.2$ & 39 & 43 & 0.027 & 0.018 & 0.001 \\
$\mathbf{1}+$ ODPB, $r=1$ & 92 & 34 & 0.030 & 0.022 & 0.041 \\
$\mathbf{1}+$ ODPB, $r=0.5$ & 68 & 34 & 0.030 & 0.021 & 0.026 \\
\hline
\end{tabular}

The influence of n-octadecyl alcohol and n-octadecylpyridinium bromide on the character of isotherms

We obtained compression isotherms at various values of molar ratio $r$, which is the number of surfactant molecules per repeating unit of $\mathbf{1}$. The representative data for $(\mathbf{1}+\mathrm{ODA})$ mixtures are shown in Figure 1 .

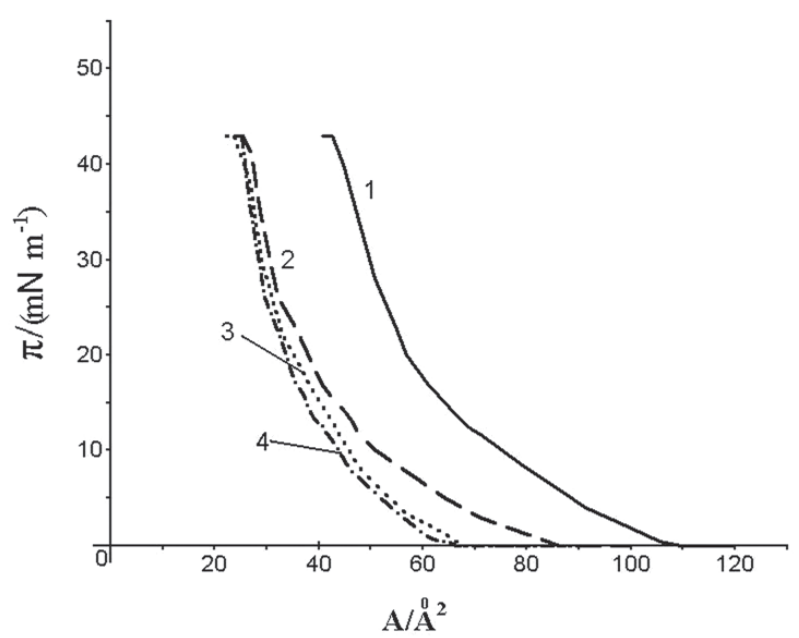

Figure 1. $\pi-A$ isotherms for $(1+\mathrm{ODA})$ mixtures on $\mathrm{Pb}^{2+}-$ containing subphases: $r=1$ (1); $r=0.5$ (2); $r=0.33$ (3); $r=0.2$ (4).

The distinct decrease in $S_{\mathrm{m}}$ along with $r$ decrease is registered in mixed layers. Then, for $r=1$ the $S_{\mathrm{m}}$ value equals $62 \AA^{2}$, which coincides with the data reported for polyamic acid derivative with $\mathrm{R}=\mathrm{H}, \mathrm{R}^{1}=\mathrm{O}-\left(\mathrm{CH}_{2}\right)_{17}-\mathrm{CH}_{3}$ : $S_{\mathrm{m}}=63 \AA^{2}$ on pure aqueous subphase. ${ }^{9}$ In Table 1 , the $S_{\mathrm{m}}$ values are given for different $r$. However, these values are somewhat lower than that without ODA addition, i.e. at $r=$ $0\left(52 \AA^{2}\right.$, see above); similar effect was reported for a system without $\mathrm{Pb}^{2+}$ ions ${ }^{9}$ and is probably caused by more tight structure of $\mathbf{1}$ monolayers containing small amounts of ODA as compared with that of pure $\mathbf{1}$ monolayers. The compressibility values, $\delta$, calculated as $\delta=-(1 / A)(\partial A / \partial \pi)_{\mathrm{T}}$, confirm such explanation (Table 1).

The variations in the limiting area per repeating unit also take place in the case of $(\mathbf{1}+$ ODPB $)$ system for 
$r=1$ and 0.5 (Table 1). At this event, some of the $\mathrm{Pb}^{2+}$ ions present in the monolayer can be replaced by ${ }^{+} \mathrm{H}_{5} \mathrm{C}_{5} \mathrm{~N}-\mathrm{C}_{18} \mathrm{H}_{37}$ ions. For example, for (1 + ODPB) system with $r=1$, the $C_{\mathrm{Pb}} / C_{\mathrm{N}}$ ratio in the corresponding Langmuir - Blodgett film drops from 0.23 to 0.014 . The effect of $\mathrm{Pb}^{2+}$ release is certainly enhanced by water-soluble complex formation of this cation with $\mathrm{Br}^{-}$anions, or even by partial $\mathrm{PbBr}_{2}$ deposition. The presence of long-tailed cationic surfactant ions results in formation of a salt with the carboxylate groups: $\mathrm{COO}^{-}{ }^{+} \mathrm{H}_{5} \mathrm{C}_{5} \mathrm{~N}-\mathrm{C}_{18} \mathrm{H}_{37}$ (see Introduction). And really, the $S_{\mathrm{m}}$ value for $(1+N, N$ dimethyloctadecylamine) mixed layers equals $80 \AA^{2}$ at $r=1$ and decreases up to $60 \AA^{2}$ at $r=0.5 .^{10}$

The difference between the $S_{\mathrm{m}}$ values obtained by us and those reported in literature (see Introduction) is probably connected with different conditions of monolayers formation (temperature, presence of metal ions, compression rate). In all the cases, equal volumes of mixed organic solvents were deposited on the aqueous subphase in our experiments.

Of course, some transition of small molecular weight fractions into the subphase cannot be excluded. However, the hysteresis curves demonstrate that this effect is of a minor nature and on the first approximation negligible. We suppose that the decrease in $S_{\mathrm{m}}$ is caused not only by diffusion of some fractions of the polymer into the aqueous phase due to competition with the lowmolecular-weight surfactant, but also by the more compact state of the mixed films. This supposition is confirmed by the stability curves, some of them are presented in Figure 2.

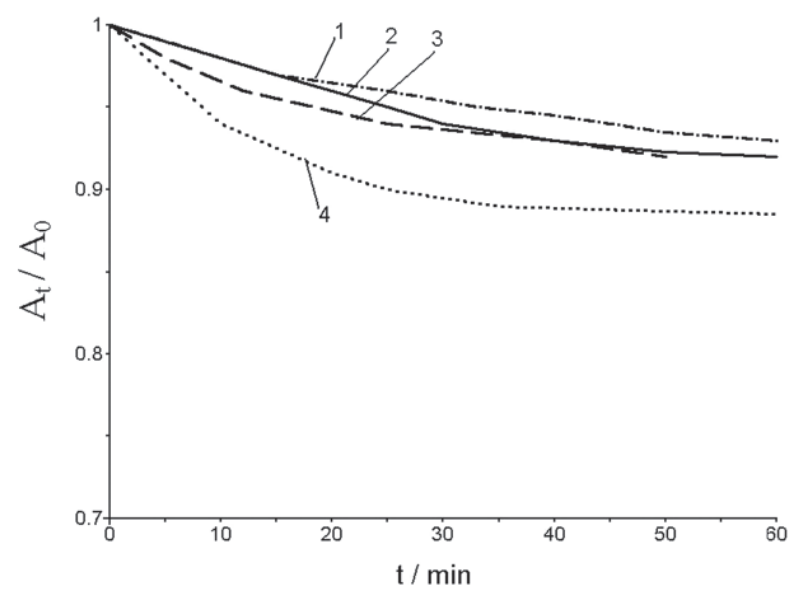

Figure 2. Stability curves for $(\mathbf{1}+\mathrm{ODA})$ mixtures: $r=0.33(1), \mathrm{Pb}^{2+}-$ containing subphase; $r=0.5(2), \mathrm{Pb}^{2+}-$ containing subphase; $r=0.2(3)$, $\mathrm{Pb}^{2+}-$ containing subphase; $r=0.2(4)-$ pure subphase.

Determination of time stability and compressionexpansion cycles is one of the methods for testing of monolayers possible leakage. ${ }^{1,22-24}$ Our results of monolayers stability studies are given below.

\section{The study of monolayers stability}

Figure 2 demonstrates alterations of $S_{\mathrm{m}}$ in the systems $\mathbf{1}+$ ODA and $\mathbf{1}+$ ODPB in time. Experiments of area change at constant surface pressure were performed by pressing 1 films to the desired surface and then maintaining the surface pressure by further movements of the compression barrier as required. In both cases, most stable are monolayers on $\mathrm{Pb}^{2+}$-containing subphase. This confirms the binding of $\mathrm{Pb}^{2+}$ to mixed monolayers: on pure subphase the stability decreases.

Isotherms of compression-expansion cycles for $(\mathbf{1}+$ ODA) mixed layers with $r=0.5$ on lead-containing subphase, at pH 5.8-6.0, are typified in Figure 3.

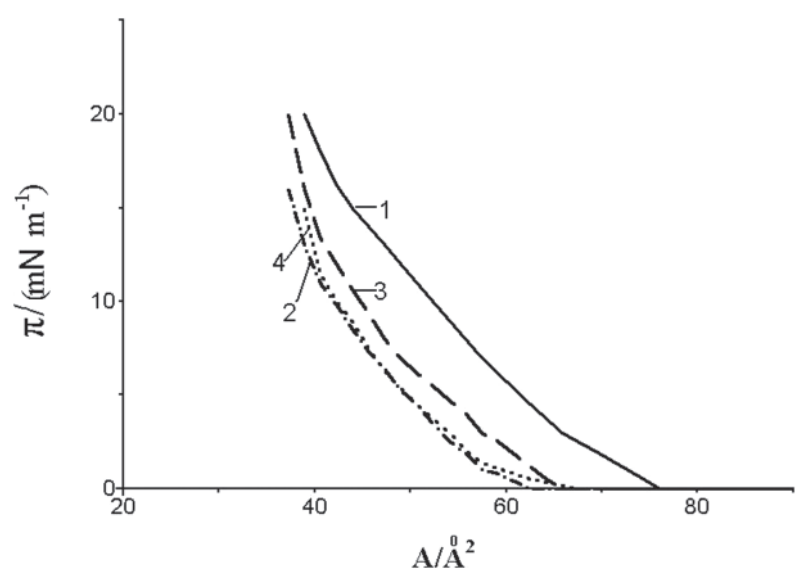

Figure 3. Compression-expansion isotherms for $(\mathbf{1}+$ ODA $)$ mixture with ratio $r=0.5$; isotherms (1), (2) and (3), (4): first and second cycles, correspondingly.

Surface pressure relaxation at monolayer compression to $\pi=20 \mathrm{mN} \mathrm{m}^{-1}$ equals $5 \mathrm{mN} \mathrm{m}^{-1}$, and after recompression it was $4 \mathrm{mN} \mathrm{m}^{-1}$. At compression of monolayer up to 10 $\mathrm{mN} \mathrm{m}^{-1}$ a decrease in relaxation is observed $\left(\Delta \pi_{1}=2.7 \mathrm{mN}\right.$ $\mathrm{m}^{-1}$ and $\left.\Delta \pi_{2}=2.2 \mathrm{mN} \mathrm{m}^{-1}\right)$. Similar effects were observed for phospholipids. ${ }^{24}$ The hysteresis value is known to increase along with the increase in maximum surface pressure of the hysteresis cycle, and the hysteresis loop area strongly depends on the deformation duration: the area increases with time. ${ }^{23}$ After the stop of deformation the observed hysteresis, i.e. the difference in $\pi$ values at the same $S_{\mathrm{m}}$ values, can be explained by (possible) partial diving of polymer chains into liquid subphase during compression, as well as increasing cohesion of polymer chains. During film expansion, the diffusion of polymer chain fragments downsunk into the aqueous phase can fall behind. On the other hand, the decrease in $S_{\mathrm{m}}$ in the second compressionexpansion cycle (Figure 3 ) at fixed $\pi$ value allows to suppose possible diving of some units of the chain into the water environment, as well as changing of macromolecule 
conformation. For instance, for the system $(\mathbf{1}+\mathrm{ODA}, r=$ 0.5 ) at $\pi=5 \mathrm{mN} \mathrm{m}^{-1}$ and $10 \mathrm{mN} \mathrm{m}^{-1}$, the decrease in $S_{\mathrm{m}}$ in the first cycle was $11 \AA^{2}$ and $9 \AA^{2}$ respectively, while in the second one it was $3 \AA^{2}$ and $2 \AA^{2}$, respectively. The curves of first and second expansions are practically identical at two-dimensional pressure of $20 \mathrm{mN} \mathrm{m}^{-1}$. The recompression curve lies somewhat below the first compression curve and demonstrates irreversible changing of the film.

\section{Dye-containing polyamic mono- and multilayers}

Dye-containing Langmuir - Blodgett multilayers are widely used in optical sensors. ${ }^{29,30}$ However, the optical and protolytic properties of such self-assembled aggregates have been studied less comprehensively than those of dyes in common liquid solutions or in organized solutions, e. g. in micellar surfactant systems. Meanwhile, high local concentrations of chromophores (fluorophores) and highly ordered structure of such systems may cause some peculiarities of the behavior of dyes. Therefore it is interesting to examine the spectral properties and protolytic equilibrium in such complicated systems, the more so, that such studies for polymeric multilayers are still rather rare. ${ }^{5,6}$

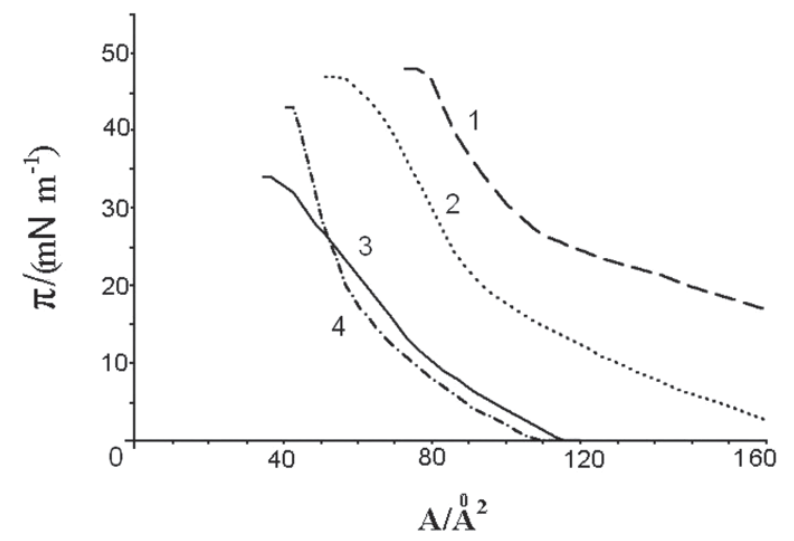

Figure 4. $\pi-A$ isotherms for $(1+$ ODPB $)$ mixture, $r=1,28$ mole $\%$ of dye 3 (1), for (1 + ODPB) mixture, $r=1$ (3), for $(\mathbf{1}+\mathrm{ODA})$ mixture, $r=$ $0.8,22$ mole $\%$ of dye $\mathbf{3}$ (2), and for ( $\mathbf{1}+\mathrm{ODA})$ mixture, $r=1$, (4). All the mixtures are obtained on $\mathrm{Pb}^{2+}-$ containing subphases.

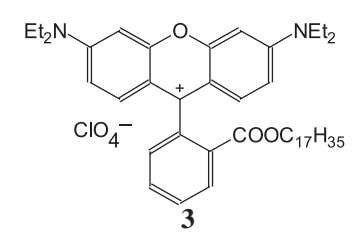

We tried to obtain stable polymer-based Langmuir Blodgett films with several dyes from hydroxyxanthene, sulfonephthalein, and azo series; however, not all of the attempts were successful. Below we present some of the results obtained.
The most simple way is to use long-tailed dyes. Typical compression curves of mixed monolayers containing highly hydrophobic water-insoluble $n$-heptadecyl rhodamine B perchlorate 3 are demonstrated in Figure 4.

The introduction of 22 mole $\%$ of the dye into the mixture of $\mathbf{1}+$ ODA at $r=0.8$ results in marked increase in the limiting area: $S_{\mathrm{m}}=112.7 \AA^{2}$, while in the system without the dye $S_{\mathrm{m}}$ is $c a .56 \AA^{2}$ (Figure 1). The $S_{\mathrm{m}}$ value in $\left(1+\right.$ ODPB) mixture $(r=1.0)$ rises from $92 \AA^{2}$ to $131 \AA^{2}$ (Figure 4) in the presence of 28 mole $\%$ of the hydrophobic rhodamine dye.

Vis absorption and emission spectra of 60-monolayer film containing the dye $\mathbf{3}$ are presented in Figure 5. Spectra are normalized at the maximum.

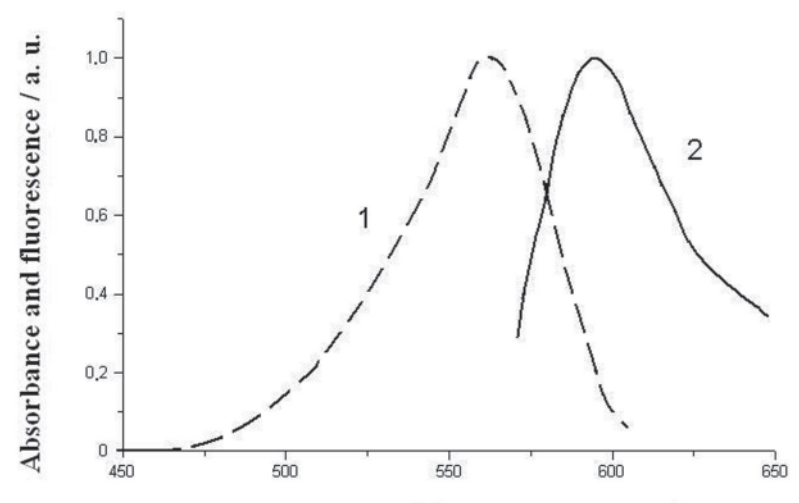

$\lambda / \mathrm{nm}$

Figure 5. Vis absorption (1) and fluorescence (2) spectra of $n$-heptadecyl rhodamine B in (1 + ODA) matrix, $r=1$, the dye 3 content 6 mole $\%$, the 60-monolayer film was obtained on $\mathrm{Pb}^{2+}-$ containing subphase, $\mathrm{pH}=$ 5.8 , at $\pi=30 \mathrm{mN} \mathrm{m}^{-1}$ (for details see the text).

Absorption and emission maxima are equal to $563 \pm 1 \mathrm{~nm}$ and $595 \pm 2 \mathrm{~nm}$, respectively. Note that it was possible to register the distinct emission spectra of the dye $\mathbf{3}$ only after alternation of dye-containing monolayers with three ODA layers, which were obtained on pure subphase, $\mathrm{pH}$ 6.0. This prevents the fluorescence quenching with $\mathrm{Pb}^{2+}$ ions as well as self-quenching. The latter is maybe the most important reason for quenching, and really, we were unable to register any emission of pure dye films prepared by Schaefer method (not described here).

On the other hand, both the variation of $\mathbf{3}$ concentration from 22 mole $\%$ to 6 mole $\%$ and alternation with ODA layers display practically no influence on the Vis absorption spectra except its intensity; such procedure is sometimes used in preparation of dye-containing films. ${ }^{31}$ Each dye-containing monolayer was alternated with three ODA monolayers, prepared on pure aqueous subphase at $\pi=28 \mathrm{mN} \mathrm{m}^{-1}$, using the Langmuir trough with two chutes. This allows to attribute the Vis absorption spectrum mainly to the monomeric species of the free rhodamine dye cation or ionic pair with perchlorate anion; the possible 
dimer formation does not manifest itself markedly, and the 'shoulder' at $520-530 \mathrm{~nm}$ is rather of vibrational nature.

Shtykov et al. ${ }^{32}$ reported compression curves of monolayers and fluorescence spectra of Langmuir Blodgett films for the anionic rhodamine dye rhodamine 200 B introduced into 2 layers in form of a salt with cetyltrimethylammonium; the results are qualitatively similar to ours. Later the behavior of rhodamine $200 \mathrm{~B}$ in Langmuir - Blodgett films based on octadecyl amine were studied by Ray and Nakahara. ${ }^{33}$

The compression isotherms of fatty acids with and without rhodamine dyes reported in literature are similar to ours. Alekseeva et al. ${ }^{34}$ studied mixtures of rhodamine B $n$-decyl ester with stearic acid, while Yonezawa et al. ${ }^{35}$ published the $\pi-A$ isotherms of two rhodamine dyes with long hydrocarbon tails at nitrogen atoms, namely $N$-octadecyl rhodamine B perchlorate and $N, N$ '-dioctadecyl rhodamine B perchlorate, mixed with arachidic acid and methyl arachidate. In all of these cases, as well as at compression of the monolayers of $N, N$ '-dioctadecyl rhodamine B perchlorate on pure water and on water containing varying concentrations of sodium $n$-dodecyl sulfate, studied by Slyadneva et al., ${ }^{36}$ competition between dye molecules and surfactants in the monolayers is evident. However, in spite of the absorption spectra in Langmuir - Blodgett films ${ }^{34}$ and reflection-absorption spectra in solid-condensed monolayers, ${ }^{36}$ our above spectral data give no reliable evidence for dimer formation (see above).

Tamai et al. ${ }^{16}$ reported the spectra of $N, N$ '-dioctadecyl rhodamine B perchlorate in mixed Langmuir-Blodgett films with arachidic acid and methylarachidate, obtained on $\mathrm{CdCl}_{2}$-containing subphase, while Ballet et al. ${ }^{31}$ studied the multilayers of the same dye with diacylphosphatidic acid, obtained from monolayers on aqueous $\mathrm{CaCl}_{2}$-containing subphase (in several cases alternated by layers of cadmium arachidate). Comparison of our data with those reported by these authors allows to conclude that phase separation during compression of the mixed monolayers, resulting in dimer formation, is not typical for polymer-based system containing $n$-heptadecyl rhodamine B.

Because the carboxylic group of the dye $\mathbf{3}$ is esterified, its spectra stay unchanged after placing into aqueous solutions within a wide $\mathrm{pH}$ region. However, the spectra of films containing some other dyes are $\mathrm{pH}$-dependent. The behavior of two of them is described below.

\section{pH Response of dye-containing Langmuir - Blodgett films based on polyamic monolayers}

Eight halogen atoms make the dye rose Bengal B hydrophobic enough to be incorporated into monolayers and then in multilayers prepared by using Schaefer method. And really, this dye in its dianionic form, $\mathrm{R}^{2-}$, is known to be bound even by anionic micelles of sodium $n$ dodecyl sulfate in aqueous media. ${ }^{37}$

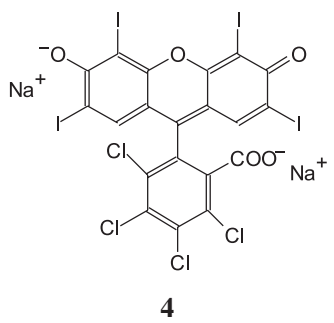

The fluorescence of $\mathrm{R}^{2-}$ species, represented as a disodium salt $\mathrm{Na}_{2} \mathrm{R}, \mathbf{4}$, is strongly quenched in polymeric films soaked into aqueous solution with $\mathrm{pH} 9.18$. Fluorescence became more distinct in Langmuir Blodgett films of the dye with ODPB, without PA and $\mathrm{Pb}^{2+}$ ions, as depicted in Figure 6. The 60-monolayer film is received at $\pi=25 \mathrm{mN} \mathrm{m}^{-1}$.

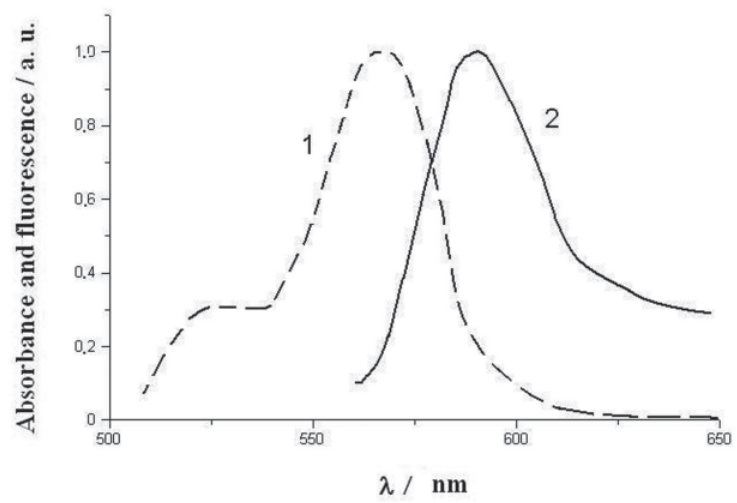

Figure 6. Vis absorption (1) and fluorescence (2) spectra of dye 4 in ODPB matrix, dye content 35 mole\%.

Absorption and emission maxima are equal to $568 \pm 1$ $\mathrm{nm}$ and $590 \pm 2 \mathrm{~nm}$, respectively. Spectra are normalized at the maximum.

However, the Vis absorption spectra of polymeric (6080)-monolayer films containing this dye demonstrate a response to the $\mathrm{pH}$ values of the aqueous solutions into which they are soaked. The protonation of the aforementioned dianion $\mathrm{R}^{2-}$ of the dye occurs stepwise:

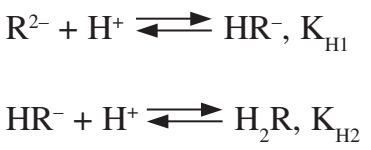

Further protonation up to cation $\mathrm{H}_{3} \mathrm{R}^{+}$formation takes place in extremely acidic media (e.g. in concentrated $\mathrm{H}_{2} \mathrm{SO}_{4}$ ). The protonation constants $K_{\mathrm{H} 1}$ and $K_{\mathrm{H} 2}$ correspond to the dissociation constants of $\mathrm{HR}^{-}$and $\mathrm{H}_{2} \mathrm{R}, K_{a 2}$ and $K_{a 1}$, respectively. The Vis spectra are typified in Figure 7.

In water, the dianion $\mathrm{R}^{2-}$ of rose Bengal $\mathrm{B}$ is characterized by the $\lambda_{\max }$ value of $548 \mathrm{~nm},{ }^{37}$ while in the (1 


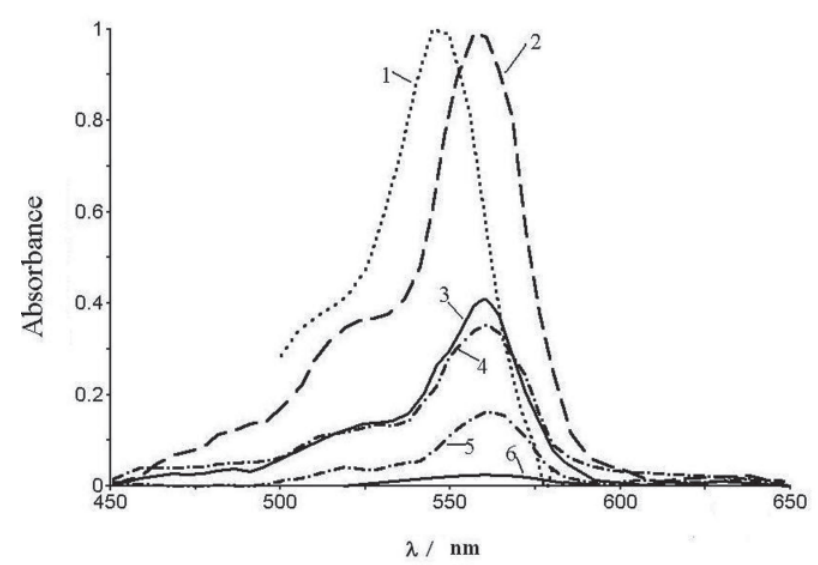

Figure 7. Vis absorption spectra of rose Bengal $\mathrm{B}$ in water, $\mathrm{pH}=12$ (1) and in a 80-monolayer film of (1+ODPB) mixtures, with $r=1$ and 28 mole $\%$ of the dye 4 , received at $\pi=25 \mathrm{mN} \mathrm{m}^{-1}$ on $\mathrm{Pb}^{2+}$ - containing subphases; the measurements were processed in aqueous solutions with $\mathrm{pH}=9.18(2), \mathrm{pH}$ $=7.5$ (3), $\mathrm{pH}=6.86$ (4), $\mathrm{pH}=4.8$ (5), and $\mathrm{pH}=1.68$ (6).

+ ODPB; $r=1$ ) matrix with $28 \%$ of $\mathbf{4}$, obtained on $\mathrm{Pb}^{2+}-$ containing subphase, the value $\lambda_{\max }=561 \pm 2 \mathrm{~nm}$ is registered after soaking in aqueous borax buffer with $\mathrm{pH}$ 9.18; these two spectra are normalized at the maximum. The character of absorption bands is typical for monomeric dye, which allows to suppose that phase segregation is highly improbable, and the absorbing/emitting species are rather separated from each other by the polymer + surfactant environments.

The set of spectra was obtained by soaking the film in aqueous buffers with different $\mathrm{pH}$ values (Figure 7); the results are numerously reproduced. After keeping in the dark for one year such dye-containing films demonstrate very similar dependence of absorption $v s$. $\mathrm{pH}$. Moreover, the freshly prepared multilayer can be repeatedly soaked in buffer solutions with $\mathrm{pH}=9.18$ and 1.68 , than again in solution with high $\mathrm{pH}$, an so on at least three times with coinciding absorption spectra at 9.18.

In our previous paper, the $\mathrm{p} K_{a}$ values in some organic and mixed solvents were collected. ${ }^{37}$ The neutral dye species are poorly soluble in water, and therefore the exact 'aqueous' $\mathrm{p} K_{a}$ values are practically unavailable. In 50\% aqueous ethanol, the $\mathrm{p} K_{a 1}$ and $\mathrm{p} K_{a 2}$ values are correspondingly 3.96 and $4.54,{ }^{38}$ in $50 \%$ aqueous 1,4-dioxane 4.22 and $5.01,{ }^{39}$ in $64 \% 1,4$-dioxane 5.79 and $6.97,{ }^{37}$ in $52 \%$ acetone 4.35 and $5.40,{ }^{37}$ in $90 \%$ acetone 6.8 and $7.7,{ }^{37}$ and in $91 \%$ dimethyl sulfoxide 3.85 and 5.72. ${ }^{37}$

On the other hand, in aqueous micellar solutions of sodium $n$-dodecyl sulfate, at bulk $\mathrm{NaCl}$ concentration $0.05 \mathrm{~mol} \mathrm{~L}^{-1}$, the 'apparent' $\mathrm{p} K_{a 1}^{a}$ and $\mathrm{p} K_{a 2}^{a}$ values are equal to 4.55 and 6.80 correspondingly, while in micellar solutions of cetyl-trimethylammonium bromide solution, with $0.05 \mathrm{~mol} \mathrm{~L}^{-1} \mathrm{KBr}$, the values are correspondingly 1.88 and $3.14 .{ }^{37}$ As the hydrophobic dye is practically completely bond both to the anionic and cationic micellar surfaces, the difference in the $\mathrm{p} K_{a}^{a}$ values strongly reflects the charge of micellar surfaces and the local electrical potentials.

In the Langmuir - Blodgett film under study, the $\mathrm{pH}$ region 6.9-7.5 approximately corresponds to the $\mathrm{p} K_{a 1}^{a}$ value, because the absorption spectra of the species $\mathrm{HR}^{-}$and $\mathrm{R}^{2-}$ are very similar (except the small red shift of the monoanionic band against the dianionic one, due to protonation of the $\mathrm{COO}^{-}$group of 4), and the neutral form $\mathrm{H}_{2} \mathrm{R}$ absorbs very slightly due to the predominance of the colorless lactonic structure. ${ }^{37}$ In this $\mathrm{pH}$ region, the carboxylic groups of PA are completely ionized and the degree of their association with $\mathrm{Pb}^{2+}$ cations is high, and the value $\mathrm{p} K_{a 1}^{a} c a .7$ reflects the influence of organic microenvironment and probable negative electrical potential of the dye location sites in the polymer matrix. The possibility of accurate $\mathrm{p} K_{a}^{a}$ determinations of two overlapping equilibria seems to be unlikely because the protonation of $\mathbf{1}$ carboxylate groups and hence the alteration of local electrical potentials of the microenvironment of the dye species take place at $\mathrm{pH}$ below 6 .

The color change of the acid-base indicator quinaldine red lies in much more acidic region. This dye was introduced into the films in form of the cation 5. While going from water to Langmuir - Blodgett film, a batochromic shift of the absorption band, from 492 $\mathrm{nm}$ to $547 \mathrm{~nm}$, was registered (Figure 8); such strong shift $(55 \mathrm{~nm})$ reflects the transfer of the dye from aqueous to organic microenvironment. The absorption spectra of this dye demonstrate a distinct $\mathrm{pH}$-response; Figure 9 shows a representative set of spectra from a larger body of data.

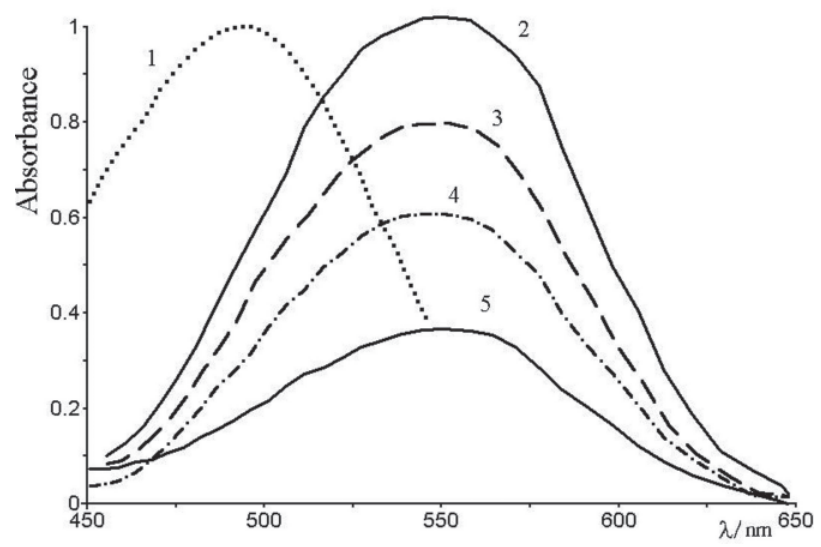

Figure 8. Vis absorption spectra of quinaldine red in water at $\mathrm{pH}=7$ (1) and in a 60-monolayer film based on (1+ODA) mixtures with $r=1$ and 18 mole $\%$ of $\mathbf{5}$, obtained on $\mathrm{Pb}^{2+}-$ containing subphase at $\mathrm{pH}=5.8$ (2); these two spectra are normalized at the maximum. Spectra of the same film sustained during 5 minutes in aqueous $\mathrm{HCl}$ solutions: $\mathrm{pH}=3.0$ (3), $\mathrm{pH}=2.24$ (4), and $\mathrm{pH}=1.55$ (5). 
The red cationic species $\mathbf{5}$ convert into colorless dication:

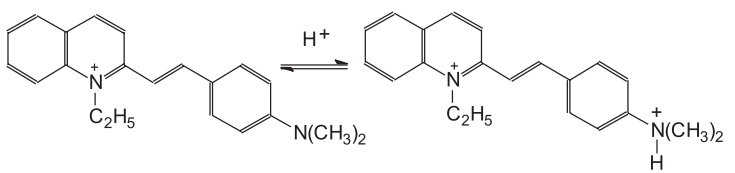

The protonation constant of the cation, $K_{\mathrm{H}}$, coincides with the dissociation constant of the dication, $K_{a}$. The apparent value, $\mathrm{p} K_{a}^{a}$, as determined by standard spectroscopic procedure from data given in Figure 9, equals $2.3 \pm 0.3$; the dilute aqueous $\mathrm{HCl}$ solutions with pH 1.55 to 3.30 are used in calculations. The variation of ionic strength of working solutions from 0.03 to $5 \times 10^{-4}$ mol L $\mathrm{L}^{-1}$ displays no distinct influence on the results.

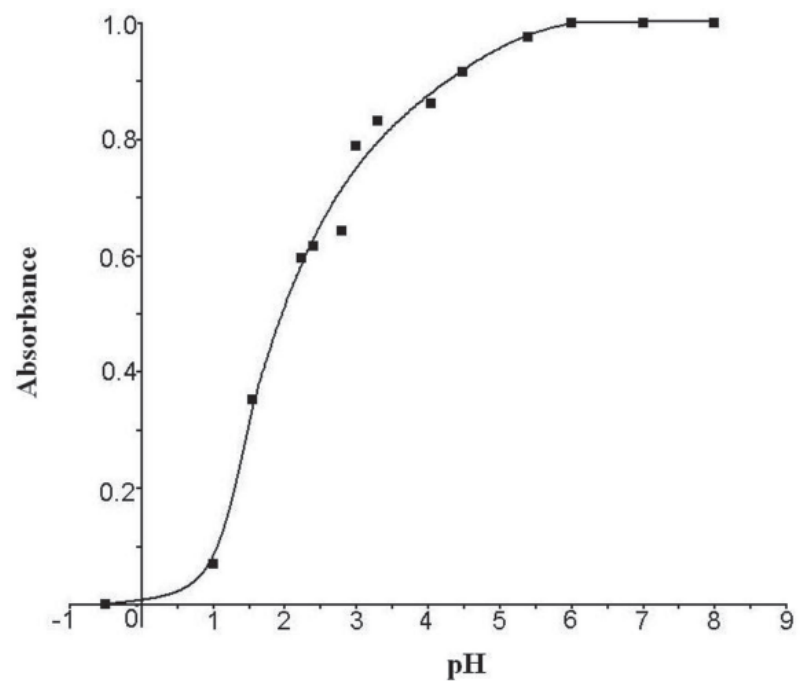

Figure 9. The $\mathrm{pH}$ dependence of absorption of quinaldine red in a 60 monolayer Langmuir - Blodgett film based on (1 + ODA) sustained for 5 min in $\mathrm{HCl}$ solutions of various concentrations; $20^{\circ} \mathrm{C}$.

The indicator immobilized in the wetted polymeric films can be regarded as placed into a water-organic mixed solvent or into self-assembled aggregate. However, the real $\mathrm{pH}$ values in the location sites of the indicator species in the wetted films can evidently differ from $\mathrm{pH}$ values of the aqueous buffers used in calculations of $\mathrm{p} K_{a}^{a}$, and the latter are conventional, the more so, that the difference may be in general case inconstant. And really, the above $\mathrm{p} K_{a}^{a}$ value varies from 2.59 at $\mathrm{pH} 3.30$ to 1.82 at $\mathrm{pH} 1.55$. However, the dependence of absorbance $v s . \mathrm{pH}$ depicted in Figure 9 is well reproducible and thus can be used as a calibration curve in optical sensors.

The thermodynamic $\mathrm{p} K$ value of quinaldine red dication in water is $2.63 ;^{40}$ hence, in PA multilayer $\Delta \mathrm{p} K_{a}^{a}=\mathrm{p} K^{a}{ }_{a}-\mathrm{p} K_{a}$ (in water $)=-0.3$. Such a shift agrees with the decrease in $\mathrm{p} K_{a}$ of cationic and dicationic acids on going from water to organic environments. In case if the local electrical potentials are negative, the apparent $\mathrm{p} K_{a}^{a}{ }_{a}$ value of quinaldine red dication increases, for example, in micellar solutions of sodium $n$-dodecyl sulfate, at bulk $\mathrm{NaCl}$ concentration $0.05 \mathrm{~mol} \mathrm{~L}^{-1}, \mathrm{pK}^{a}$ equals $3.19, \Delta \mathrm{p} K_{a}^{a}=+0.6 .^{40}$ On the other hand, in the acidic $\mathrm{pH}$ region the complete protonation of carboxylate groups of PA certainly takes place $\left(\mathrm{COO}^{-} \rightarrow \mathrm{COOH}\right)$, resulting in sharp increase in the surface electrical potential. Due to the presence of $\mathrm{Pb}^{2+}$ ions in the multilayers, the electrical potentials in the location sites of the indicator may be even positive, which also contributes to the decrease $\mathrm{p} K^{a}{ }_{a}$. And really, the $\Delta \mathrm{p} K^{a}{ }_{a}$ values of methyl orange and benzopurpurin $4 \mathrm{~B}$, corresponding to the acidic region of $\mathrm{pH}$, are negative in multilayers of $\mathbf{2}$ salt with $N, N$-dimethyloctadecylamine. ${ }^{5,32}$

Besides, in addition to the alterations in the state of PA carboxylic groups in acid region the (partial) release of $\mathrm{Pb}^{2+}$ ions can occur, analogous to the well-known effect of decrease of the fractions of doubly charged metal cations from the Langmuir monolayers of fatty acids obtained at relatively low $\mathrm{pH} .{ }^{19}$

Thus, the results of preliminary measurements with indicators do not contradict the knowledge about the state of PA carboxylic groups. To obtain further, more definite results with indicators of various types it is necessary to take into account the (possible) ion association of anionic dye species with $\mathrm{Pb}^{2+}$ and $\mathrm{ODP}^{+}$cations as well as of cationic ones with $\mathrm{COO}^{-}$groups of PA. However, it can be stated that the dye-containing polymer-based multilayers studied in this work are rather stable, the results are reproducible, and therefore the Langmuir Blodgett films of this kind can be used in optical sensors and related devices.

The behavior of indicator systems in polymeric multilayers stabilized with doubly charged metal cations demands more detailed and versatile investigations.

\section{Conclusions}

The presence of $\mathrm{Pb}^{2+}$ ions in the aqueous subphase favors keeping up polyamic acid with one $\mathrm{COOH}$ group per repeating unit, 1, on the water surface. Introduction of either acid or alkali impairs the stability of monolayers; optimal conditions for formation of $\mathbf{1}$ films on water/air interfaces are following: $1 \times 10^{-5} \mathrm{~mol} \mathrm{~L}^{-1}$ lead nitrate at $\mathrm{pH}$ 5.8-6.0. The limiting area per repeating unit, $S_{\mathrm{m}}$, equals $(52 \pm 2) \AA^{2}$ at $20{ }^{\circ} \mathrm{C}$. The addition of $n$-octadecyl alcohol and especially $n$-octadecylpyridinium bromide results in $\pi_{c}$ increase. 
The limiting area per repeating unit, $S_{\mathrm{m}}$, increases along with the increase of surfactant fraction in the initial (1 $+n$-octadecyl alcohol) and $(\mathbf{1}+n$-octadecylpyridinium bromide) mixtures.

Basing on the above polyamic monolayers, were fabricated stable Langmuir - Blodgett multilayers containing dyes of various types. The (60-80)monolayer films were studied Vis-spectroscopically, their absorption and emission was registered. Typical monomeric absorption and emission spectra were registered for $n$-heptadecyl rhodamine B; dimer formation seems less probable in polymer-based matrix. Films containing rose Bengal $\mathrm{B}$ and quinaldine red manifest themselves as $\mathrm{pH}$-sensitive after soaking in aqueous buffer solutions. The 'apparent' $\mathrm{p} K_{a}^{a}$ value of quinaldine red as determined by standard spectroscopic procedure is $2.3 \pm 0.3$. Such stable dye-containing polymeric self-assembled aggregates with reproducible spectral and acid-base properties can be used in optical sensors and related devices.

\section{Supplementary Information}

In addition to the data presented in the paper, typical examples of compression isotherms, a dependence of $r$ vs. $S_{\mathrm{m}}$, and stability curves are available, free of charge at http://jbcs.sbq.org.br, as pdf file.

\section{Acknowledgments}

We are grateful to Professor S. N. Shtykov, Dr. T. Yu. Rusanova, and Dr. D. A. Gorin, Saratov State University, Russia, for providing valuable information of the peculiarities of their experiments, ${ }^{5,6}$ as well as to Dr. V. I. Alekseeva, Research Institute of Organic Intermediates and Dyes, Moscow, Russia, for supplying us with $n$-heptadecyl ester of rhodamine B perchlorate, to Dr. M.V. Dobrotvorskaya, Institute for Single Crystals, National Academy of Sciences of Ukraine, for the X-ray photoelectron spectroscopy measurements, and to Dr. A. D. Roshal, Kharkov National University, for placing at our disposal the Hitachi F-4010 spectrofluorometer. We also thank the referees for valuable comments.

\section{References}

1. Arslanov, V. V.; Usp. Khim. 1994, 63, 3.

2. Uekita, M.; Awaji, H.; Murata, M. Proc. $3^{\text {rd }}$ Int. Symp. on Molecular Electronic Devices, North-Holland: Amsterdam, 1988, p. 531.

3. Suzuki, M.; Thin Solid Films 1989, 180, 253.
4. Uekita, M.; Awaji, H.; Murata, M.; Mizunuma, S.; Thin Solid Films 1989, 180, 271.

5. Shtykov, S. N.; Klimov, B. N.; Smirnova, T. D.; Glukhovskoi, E. G.; Istrashkina, E. V.; Sumina, E. G.; Zh. Fiz. Khim. 1997, 71, 1292.

6. Shtykov, S. N.; Klimov, B. N.; Naumenko, G. Yu.; Mel'nikov, G. V.; Smirnova, T. D.; Glukhovskoi, E. G.; Rusanova, T. Yu.; Gorin, D. A.; Zh. Fiz. Khim. 1999, 73, 1689.

7. Baker, S.; Seki, A.; Seto, J.; Thin Solid Films 1989, 180, 263.

8. Savin, Yu.; Dobrotvorskaya, M.; Tolmachev, A.; Functional Materials 1999, 6, 930.

9. Uekita, M.; Awaji, H.; Murata, M.; Thin Solid Films 1988, 160, 21.

10. Nishikata, Y.; Kakimoto, M.; Morikawa, A.; Imai, Y.; Thin Solid Films 1988, 160, 15.

11. Mishuk, T.; Eyrich, F. In Monomolecular Layers.; Taubman, A.B., ed.; Izd. Inostr. Lit.: Moscow, 1956, p. 25.

12. Lascevsky, A.; Ringsdorf, H.; Schmidt, G.; Thin Solid Films 1985, 134, 157.

13. Fukuda, K.; Shibasaki, Y.; Nakahara, H.; Thin Solid Films 1988, 160, 43.

14. Kumenura, H.; Kasuga, T.; Watanabe, T.; Miyata, S.; Thin Solid Films 1989, 178, 175.

15. Bezkrovnaya, O. N.; Mchedlov-Petrossyan, N. O.; Savvin, Yu. N.; Zh. Fiz. Khim. 2003, 77, 2206.

16. Tamai, N.; Yamazaki, T.; Yamazaki, I.; Chem. Phys. Lett. 1988, 147, 25.

17. Schwartz, D. K.; Garnaes, J.; Viswanathan, J.; Zasadzinski, J. A. N.; Science 1992, 257, 508.

18. Peng, J. B.; Barbes, G. T.; Gentle, I. R.; Adv. Colloid Interface Sci. 2001, 91, 163.

19. Kurnaz, M. L.; Schwartz, D. K.; J. Phys. Chem. 1996, 100, 11113.

20. Ivanova, A.; Kurnaz, M. L.; Schwartz, D. K.; Langmuir 1999, 15, 4622 .

21. Kurnaz, M. L.; Schwartz, D. K.; Phys. Rev. E 1997, 56, 3378.

22. Albrecht, O.; Thin Solid Films 1989, 178, 93.

23. Dimitrov, D. S.; Zh. Fiz. Khim. 1984, 58, 458.

24. Schildkraut, J.; Lewis, A.; Thin Solid Films 1985, 134, 13.

25. Adrova, N. A.; Bessonov, M. L.; Laius, L. A.; Rudakov, A. P.; Polyimides: A New Class of Thermally Stable Polymers. Nauka: Leningrad, 1968.

26. Adamson, A. W. The Physical Chemistry of Surfaces (Russian translation), Mir: Moscow, 1979.

27. Potekhin, A.A., ed.; The Properties of Organic Compounds: A Handbook, Khimiya: Leningrad, 1984.

28. Martell, A.; Smith, R. Critical Stability Constants, Plenum: New York, 1982. Vol. 5.

29. Hassan, A. K.; Ray, A. K.; Nabok, A. V.; Davis, F.; Sens. Actuator B - Chem. 2001, 77, 638.

30. Worsfold, O.; Dooling, C. M.; Richardson, T. H.; Vysotsky, M. O.; Tregonning, R.; Hunter, C. A.; Malins, C.; J. Mater. Chem. 2001, 11, 399. 
31. Ballet, P.; Van der Auweraer, M.; De Schryver, F. C.; Lemmetyinen, H.; Vuorimaa, E.; J. Phys. Chem. 1996, 100, 13701.

32. Shtykov, S. N.; Rusanova, T. Yu.; Smirnova, T. D.; Gorin, D. A.; Zh. Anal. Khim. (Russ. J. Anal. Chem., English translation) 2004, 59, 198.

33. Ray, K.; Nakahara, H. J.; Phys. Chem. B 2002, 106, 92.

34. Alekseeva, V. I., Ibraev, N. Kh.; Lukyanets, E. A.; Marinina, L. E.; Savvina, L. P.; Satybaldina, D. Zh.; Zh. Fiz. Khim. (Russ. J. Phys. Chem.) 1999, 73, 2217.

35. Yonezawa, N.; Ohno, M.; Suga, S.; Wataya, K.; Hada, H.; Nippon Kagaku Kaishi, J. Chem. Soc. Jpn. 1987, 1, 116.
36. Slyadneva, O.; Harata, A.; Hatano, Y.; J. Coll. Interface Sci. 2003, 260, 142.

37. Mchedlov-Petrossyan, N. O.; Rubtsov, M. I.; Lukatskaya, L. L.; Zh. Obsh. Khim. (Russ. J. General Chem., English translation) 2000, 70, 1177.

38. Lenquel, J.; Vecernik, J.; Krtil, J.; Radiochem. Radioanal. Lett. 1982, 54, 111.

39. Amat-Guerri, F.; Lopez-Gonzalez, M. M. C.; Sastre, R.; Martinez-Utrilla R.; Dyes Pigments 1990, 13, 219.

40. Mchedlov-Petrossyan, N. O.; Differentiation of the Strength of Organic Acids in True and Organized Solutions, Kharkov National University: Kharkov, 2004.

Received: October 29, 2005

Published on the web: April 28, 2006 


\title{
The Influence of Lead (II) Ions Introduced into the Subphase on the Stability of Mixed 'Polyamic Acid + Surfactant' Monolayers and Manufacturing of Dye-containing Langmuir - Blodgett Polymeric Films
}

\author{
Olga N. Bezkrovnaya, ${ }^{a}$ Nikolay O. Mchedlov-Petrossyan, ${ }^{*, b}$ Yuriy N. Savvin, ${ }_{b}^{a}$ Aleksandr V. Tolmachev ${ }^{a}$ \\ and Natalya A. Vodolazkaya \\ ${ }^{a}$ Institute for Single Crystals, National Academy of Sciences of Ukraine, Lenin Pr. 60, Kharkov, 61001 Ukraine \\ ${ }^{b}$ Department of Physical Chemistry, V.N. Karazin Kharkov National University, Svoboda Sq. 4, \\ Kharkov, 61077, Ukraine
}

The conditions for the preparation of monolayers of polyamic acid (PA) with one $\mathrm{COOH}$ group per repeating unit on aqueous subphases are described. It is revealed that the presence of $\mathrm{Pb}^{2+}$ ions in the aqueous subphase favors keeping up the polymer on the water surface, while the monolayers are unstable on the pure aqueous subphase. The behavior of PA films on water/air interfaces is examined mainly at $\mathrm{pH} 5.8-6.0$ and $1 \times 10^{-5} \mathrm{~mol} \mathrm{~L}^{-1}$ lead nitrate. The influence of $n$-octadecyl alcohol and $n$-octadecylpyridinium bromide on the character of isotherms and stability of monolayers is studied. The limiting area per repeating unit, $S_{\mathrm{m}}$, increases along with the increase of surfactant fraction in the initial (PA $+n$-octadecyl alcohol) and (PA + $n$-octadecylpyridinium bromide) mixtures. The $S_{\mathrm{m}}$ values, collapse pressures, and compressibilities of the films are tabulated. Basing on these polyamic monolayers, Langmuir - Blodgett (60-80)-monolayer films containing various dyes (a rhodamine dye, rose Bengal B, and quinaldine red) are fabricated by depositing on glass (quartz) support by Schaefer method. Absorption and emission spectra of these films are registered. The dye content was as a rule 6 to $\approx 30$ mole $\%$. Vis absorption spectra of plymeric (60-80) monolayer films containing rose Bengal $\mathrm{B}$ and quinaldine red, measured after soaking in aqueous buffer solution, appeared to be sensitive to the $\mathrm{pH}$ values of the latter. The 'apparent' value of quinaldine red in (PA + octadecyl alcohol) films, as determined by standard spectroscopic procedure, equals $2.3 \pm 0.3$. Such $\mathrm{pH}$ response of polymeric multilayers can be used in sensors.

* e-mail: mchedlov@univer.kharkov.ua
Polyamic acids, $\mathbf{1}$ and $\mathbf{2}$, have the general formula given below

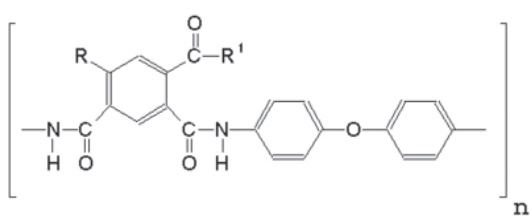

$\mathbf{1}$ is (4,4'-diphenyloxide)-2-carboxyisophthalamide, with $\mathrm{R}=\mathrm{H}, \mathrm{R}^{1}=\mathrm{OH}$, and $\mathbf{2}$ is (4,4'-diphenyloxyde)-4,6dicarboxyisophthalamide, with $\mathrm{R}=\mathrm{COOH}, \mathrm{R}^{1}=\mathrm{OH}$.

Some typical compression isotherms of $\mathbf{1}$ at $20.0 \pm$ 0.05 , stability curves, and $S_{\mathrm{m}}$ dependences vs. the number of surfactant molecules per repeating unit of $\mathbf{1}, r$, are given below.

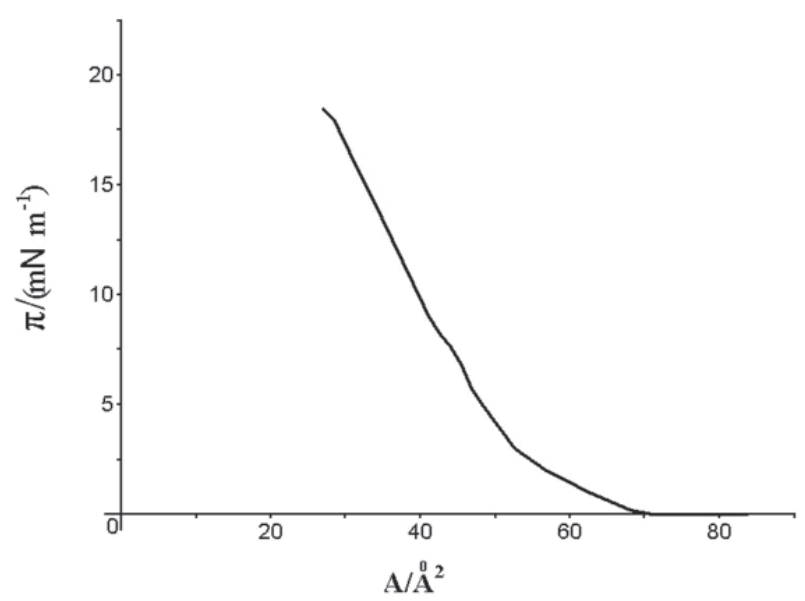

Figure 1S. $\pi-A$ isotherm of $\mathbf{1}$ on $\mathrm{Pb}^{2+}$-containing subphase. 


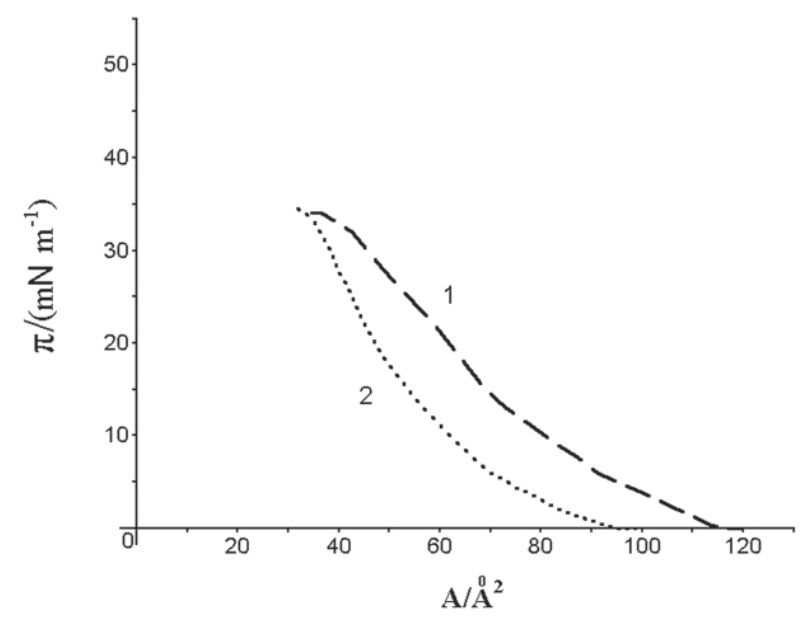

Figure 2S. $\pi-A$ isotherms for $(\mathbf{1}+n$-octadecylpyridinium bromide $)$ mixtures on $\mathrm{Pb}^{2+}$ - containing subphases: $r=1(1) ; r=0.5$ (2).

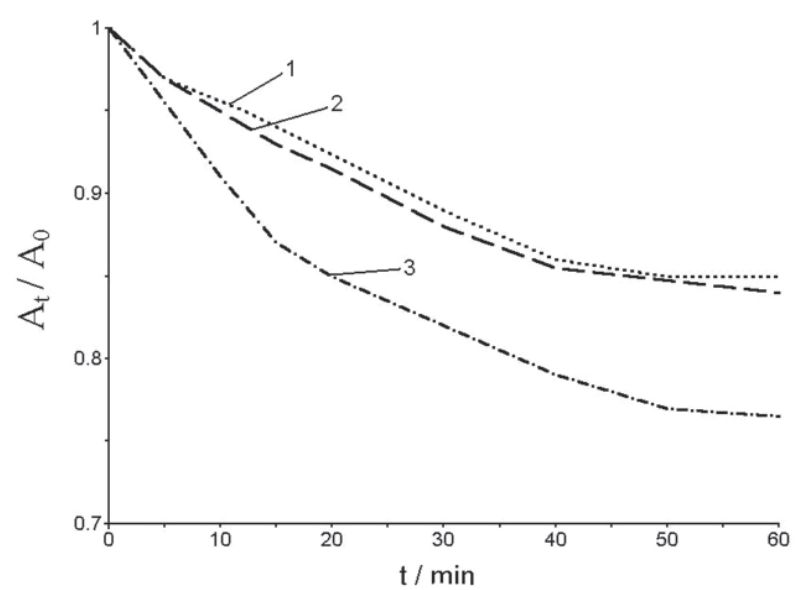

Figure 3S. Stability curves for $(\mathbf{1}+n$-octadecylpyridinium bromide $)$ mixtures: $r=1(1), \mathrm{Pb}^{2+}$-containing subphase; $r=0.5(2), \mathrm{Pb}^{2+}-$ containing subphase; $r=1$ (3) - pure subphase.

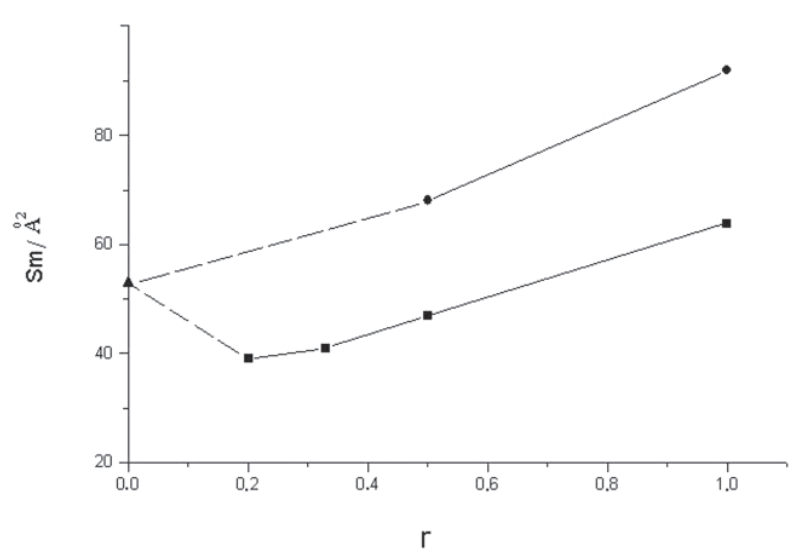

Figure 4S. The dependence of $r$ vs. $S_{\mathrm{m}}$ for $(\mathbf{1}+n$-octadecylpyridinium bromide) mixtures (- - ) and $(\mathbf{1}+n$-octadecyl alcohol $)$ mixtures (一- - - ) on $\mathrm{Pb}^{2+}-$ containing subphases; the point ( $-\mathbf{A}-$ ) corresponds to pure $\mathbf{1}$ on $\mathrm{Pb}^{2+}-$ containing subphase. 